\section{SCALER WITH 70 TIPS}

The Varios 970 ultrasonic scaler from NSK can be used for perio, endo, hygiene and minimal intervention treatment techniques, simply by exchanging the tip - and with a choice of over 70 tips, there is always one to meet your needs.

Each Varios 970 LUX is supplied, as standard, with a twin LED handpiece, three tips, three tip wrenches and an autoclavable container. The twin LEDs deliver shadow-free illumination to the entire treatment field, allowing faster and more accurate treatment. The Varios 970 has a very useful

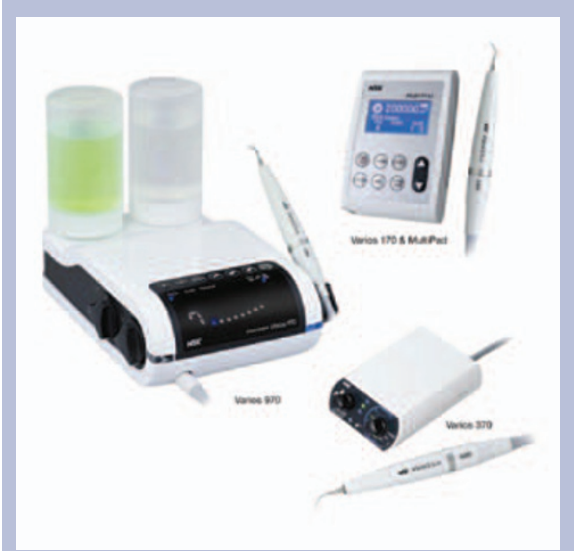

second solution container, allowing for the easy change of irrigants during treatment. The unit also has three power ranges: Perio, Endo and General, that are easily selected by the push of a button. The Varios 970 incorporates the brand new NSK iPiezo control board featuring the latest and most advanced standards in auto feedback technology, ensuring a smoother, more efficient performance. Whether you are ultrasonically scaling, endodontically shaping or preparing minimal intervention cavities, the Varios 970 is your ultrasonic unit of choice.

Those looking for a more compact unit would benefit from the Varios 370 , specifically designed as a portable control unit for easy installation into any dental unit. The Varios 370 is available in non-optic and is suitable for a variety of clinical procedures including perio, endo and general procedures. The Varios is also available as a built-in unit - Varios 170, which can be used in conjunction with NSK's new Multipad to easily control all its functions.

Reader response number 57

\section{TAX EFFICIENT FINANCE}

Applying for Braemar's popular Tax Funding Facility can take the sting out of your practice's tax bill. Conserve your cash by arranging a tax loan from Braemar Finance.

Braemar Finance's Tax Funding Facility is simple to arrange, has fixed monthly repayments, free CHAPS transfer to your bank account on completion; flexible repayment terms; leaves your investments untouched and has a fast turnaround.

Braemar Finance has a range of tax efficient finance solutions.

Reader response number 58

\title{
WRIGLEY CELEBRATES CENTENARY WITH TOOTH FAIRY FUND
}

To mark their one hundredth year in the UK, Wrigley has donated $£ 100,000$ to the British Dental Health Foundation and is also a platinum sponsor of National Smile Month.

Wrigley, whose products include Wrigley's Extra and Extra Ice White sugarfree gum, has founded The Wrigley Tooth Fairy Fund to further enhance the work they do in helping to improve the oral health of the British public.
The Tooth Fairy Fund has donated $£ 100,000$ to the Foundation who will use the financial support for an oral health education project whereby primary care trusts (PCTs) can bid for funds to create or support innovative on-the-ground oral care projects.

Wrigley hopes that PCTs will come back with some innovative ideas on how they can use the donation.

Reader response number 59 